\title{
HYDROLOGICAL ASPECTS OF THE MESOSCALE ALPINE PROGRAMME: FINDINGS FROM FIELD EXPERIMENTS AND SIMULATIONS
}

\author{
R. Ranzi ${ }^{1}$, B. Bacchi ${ }^{1}$, M. Zappa ${ }^{2}$ \\ ${ }^{1}$ Department of Civil Engineering, University of Brescia, Italy \\ ${ }^{2}$ WSL, Birmensdorf, Switzerland \\ E-mail: ,ranzi@ing.unibs.it
}

\begin{abstract}
Results of the Mesoscale Alpine Programme provide some answers to basic scientific questions of hydrological relevance posed in its scientific plan i.e:

1. verify the forecasting capabilities of a hydrological flood model, forced by the special measurements or coupled with advanced mesoscale atmospheric prediction models;

2. assess the role of the water storage in reservoirs on the runoff generation during floods in mountainous regions;

3. study the influence of soil moisture conditions prior to flood events in determining the production of runoff and investigate the capabilities and limitations of some soil moisture monitoring techniques over rugged terrain.

Summary results from investigations in some areas in the southern (Toce, Ticino, Verzasca and Maggia watersheds) and northern (Ammer watershed) side of the Alps during the Mesoscale Alpine Programme and the 1999 Special Observing Period experiment are presented.
\end{abstract}

Keywords - Hydrology, flood forecasting, reservoirs, soil moisture,

\section{FLOOD FORECASING USING COUPLED HYDRO-METEOROLOGICAL MODELS}

The first scientific objective of hydrological interest in the Mesoscale Alpine Programme was to demonstrate in real-time or near real-time the forecast capabilities of hydrological flood models, forced by special measurements or coupled with advanced mesoscale atmospheric models. Prior to the Special Observing Period (Bougeault et al., 2001) the Lago Maggiore and the Ammer watershed (see Fig. 1) areas were investigated, from a hydrological point of view, within the RAPHAEL Project (Bacchi and Ranzi, 2003). In that project several combinations of hydrological and meteorological mesoscale models were tested for simulating severe floods occurred in those watersheds (Jasper et al., 2002; Montaldo et al., 2002; Ludwig et al., 2003). Then, during the Special Observing period using two modelling chains it was possible, indeed, to issue runoff forecasts in advance to the major flood events: one, DIMOSOP, was forced by the BOLAM meteorological forecasts (Ranzi et al., 2003) and a second, WATFLOOD, was forced by the MC2 model's output (Benoit et al., 2003). Results were, on average, quite satisfactorily for both the modelling schemes, thus showing potentials, but also some limitations, of a coupled use of hydrological and mesoscale meteorological models for flood forecasting. By summarising the results of several combinations of rainfall data (observed by raingauge networks or radar and simulated or predicted by mesoscale models) and hydrological models (see also Jasper and Kaufmann, 2003; Bacchi et al., 2002) it can be said that today a time horizon of flood warning of one-two days seems realistic in basins lager than 1000-2000 $\mathrm{km}^{2}$. For basins of this size one to two days of flood forecasts warning time seem to be realistic, resulting in peak errors predicted with a bias of about $\pm 30 \%-50 \%$, on average, and uncertainties up to $60 \%$ in terms of standard error of a multi-model prediction vs. observed peak flow (Grossi and Kouwen, 2004; Ranzi, 2005)

\section{EFFECT OF RESERVOIRS}

The second aspect that was addressed was the role of some man-influenced initial conditions of the surface water system, in particular the water storage in reservoirs, on the runoff generation during floods. The role of reservoirs can be significant depending on the fraction of the basin gauged by artificial lakes and the storage volume. In areas heavily exploited for hydropower generation, as the Toce basin which is quite representative of many Alpine basins, the data of five major floods occurred in the past decade show that reservoirs can reduce flood volumes of about $10 \%$, as a reference order of magnitude, in midsize basins. During the SOP hydropower companies transmitted on a regular basis data on the water level at some major reservoirs, thus giving useful 


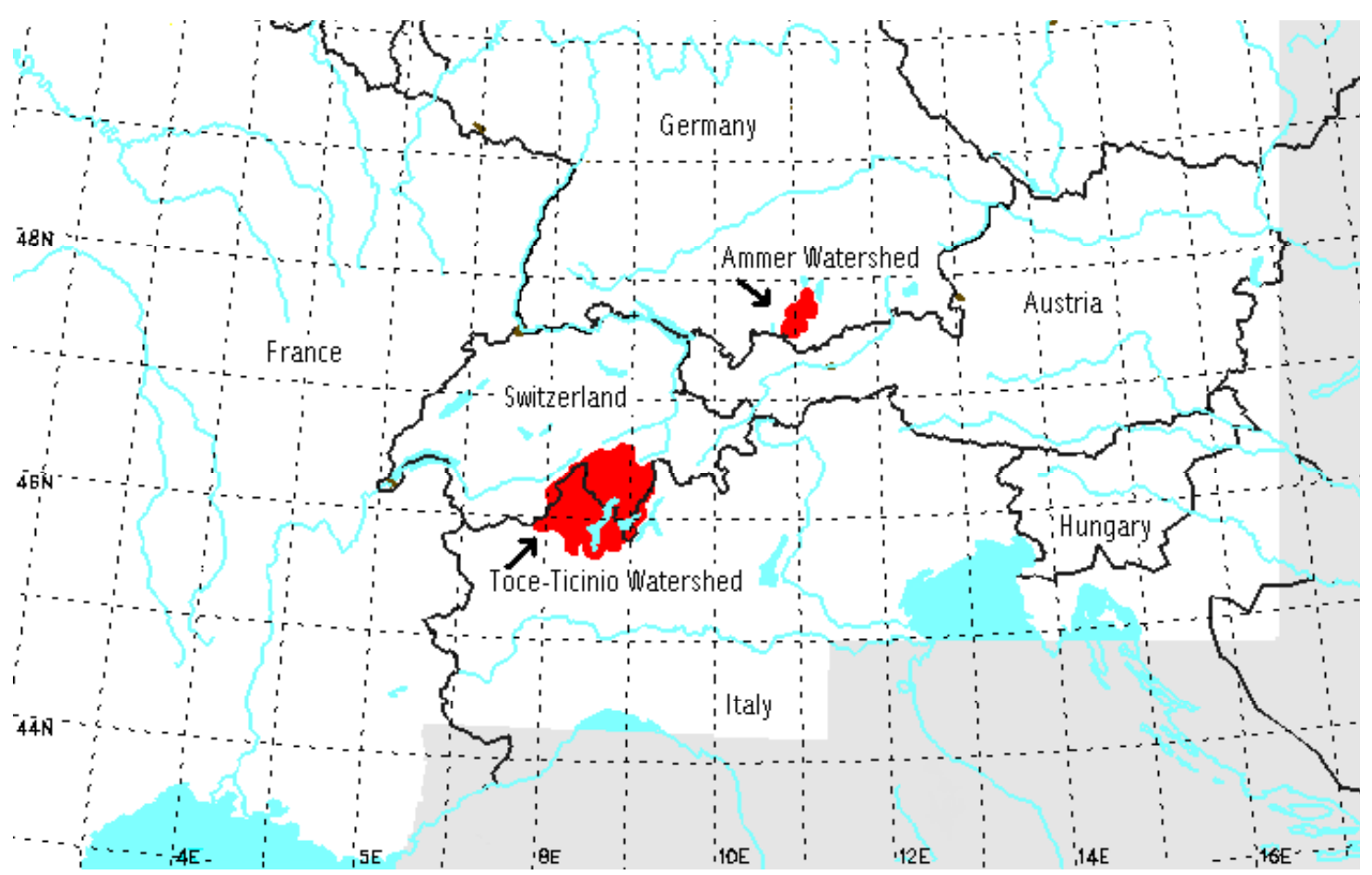

Figure 1. Location of the two investigated areas, the Toce-Ticino (including the Maggia and Verzasca) and the Ammer watershed, in the Bavarian Alps.

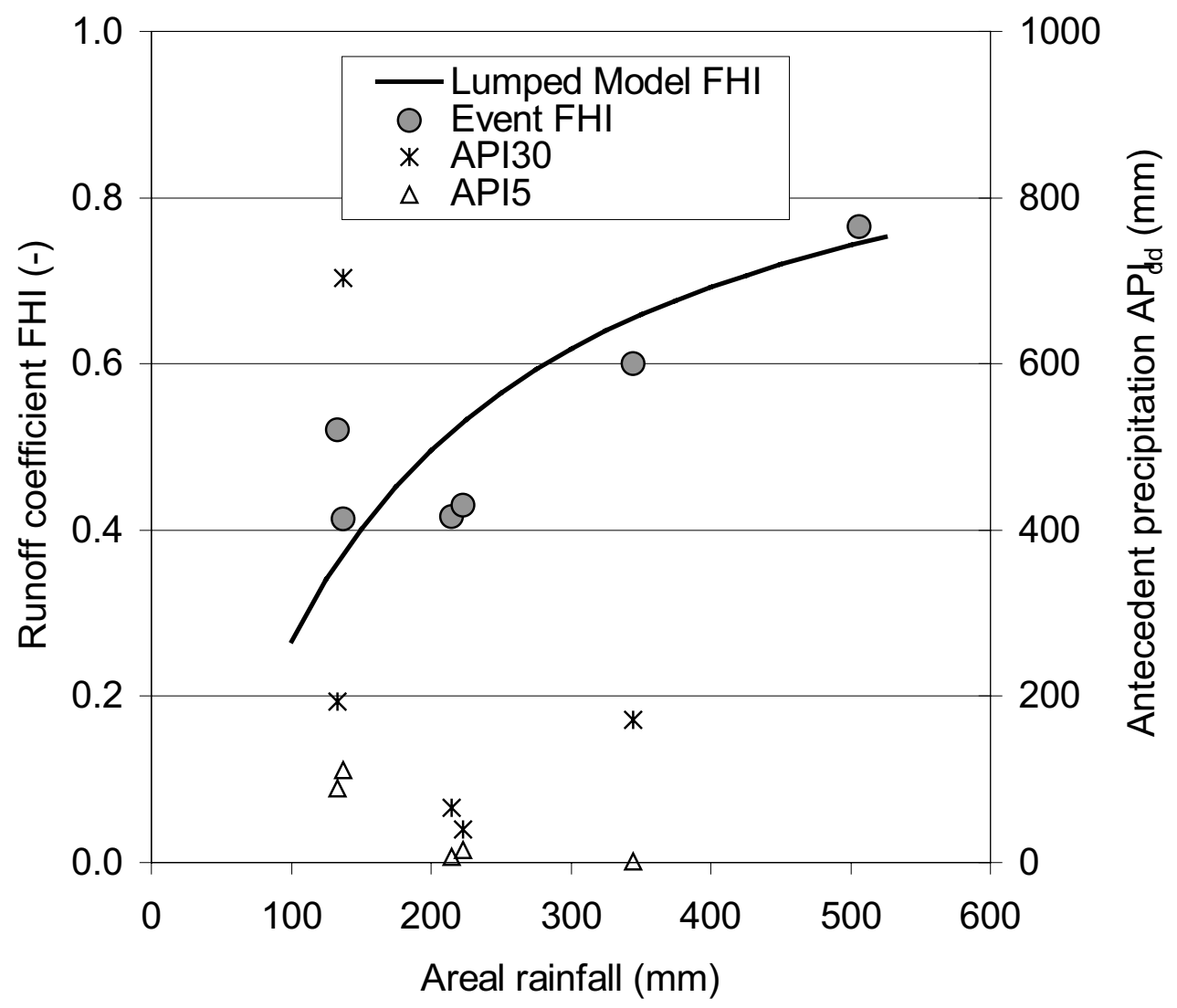

Figure 2. The runoff coefficient for 6 major floods in the Toce basin, including the IOP $2 b$ event, is represented on the left axis together with the theoretical curve of a conceptual model. On the right axis the 5 days and 30 days prior to the event precipitation. 
indications on the residual storage capacities of reservoirs and their potential effect on the reduction of runoff volumes downstream the dams. For the major flood in the Toce river, that occurred during the September 20 (IOP-2) event, a reduction of about $10 \%$ of the total flood volume was observed.

\section{SOIL MOISTURE}

The third objective was to study the role of soil moisture prior to flood events in determining the production of runoff. During the SOP soil moisture was sampled on a continuous time basis at five sites and, with major spatial detail, during the four missions of a helicopter-borne microwave radiometer in the $\mathrm{C}, \mathrm{X}$ and $\mathrm{L}$ band and different polarization (Macelloni et al., 2003). The sensitivity of the radiometer to different surface types was confirmed, although electromagnetic interferences prevented a completely successful use of the microwave antennas for soil moisture monitoring in the investigated area. The recent literature confirms that also active microwave sensors, although promising, are still far from being effective for soil moisture monitoring in mountain areas because the effect of surface roughness and topography prevents. In summary sever difficulties remain in monitoring soil moisture in mountain catchments.

Ground and laboratory measurements confirmed a relatively high variability of the soil moisture content during the Special Observing Period (Zappa and Gurtz, 2003; Menziani et al., 2003). It seems, however, that the role of soil moisture in areas covered by limited soil depths, as many steep mountain catchments, is less relevant than expected. As shown by Fig. 2 and as reported in Tab. 1 for example, different values of antecedent precipitation do not affect dramatically the resulting runoff coefficient, at least during major floods, thus indicating a minor sensitivity to initial soil moisture conditions, than generally assumed, of the hydrological response of soils to precipitation forcing. This result shoudl be confirmed by further investigations.

Table 1. Event data for major floods in the Toce, Ticino and Ammer basins.

$\mathrm{API}_{30}$ : rainfall in the 30 days prior to the event, $\mathrm{API}_{5}$ : rainfall in the 5 days prior to the event, $\mathrm{P}$ : rainfall event volume, Q: runoff volume, $\Phi$ : runoff coefficient.

\begin{tabular}{|c|c|c|c|c|c|c|}
\hline Event & Date & $\begin{array}{l}\mathrm{API}_{30} \\
(\mathrm{~mm})\end{array}$ & $\begin{array}{l}\mathrm{API}_{5} \\
(\mathrm{~mm})\end{array}$ & $\begin{array}{c}\mathrm{P} \\
(\mathrm{mm})\end{array}$ & $\begin{array}{c}\mathrm{Q} \\
(\mathrm{mm})\end{array}$ & $\begin{array}{l}\Phi \\
(-)\end{array}$ \\
\hline \multicolumn{7}{|c|}{ Toce at Candoglia $\left(1532 \mathrm{~km}^{2}\right)$} \\
\hline tt1 & 22-25 Sep. 1993 & 171 & 2 & 345 & 207 & 0.60 \\
\hline $\mathrm{tt} 2$ & 11-14 Oct. 1993 & 703 & 111 & 137 & 57 & 0.41 \\
\hline $\mathrm{tt} 3$ & 3-6 Nov. 1994 & 66 & 7 & 215 & 89 & 0.42 \\
\hline $\mathrm{tt} 4$ & 27-30 Jun. 1997 & 194 & 89 & 133 & 70 & 0.52 \\
\hline IOP2b & 19-21 Sep. 1999 & 39 & 15 & 223 & 96 & 0.43 \\
\hline $\mathrm{tt} 5$ & $12-16$ Oct. 2000 & & & 506 & 387 & 0.77 \\
\hline \multicolumn{7}{|c|}{ Ticino at Bellinzona $\left(1515 \mathrm{~km}^{2}\right)$} \\
\hline tt1 & 22-25 Sep. 1993 & 241 & 3 & 216 & 91 & 0.42 \\
\hline $\mathrm{tt} 2$ & 11-14 Oct. 1993 & 673 & 182 & 154 & 118 & 0.77 \\
\hline $\mathrm{tt} 3$ & 3-6 Nov. 1994 & 60 & 3 & 101 & 35 & 0.34 \\
\hline tt4 & 27-30 Jun. 1997 & 238 & 73 & 138 & 90 & 0.65 \\
\hline $\mathrm{IOP} 2 \mathrm{~b}$ & 19-21 Sep. 1999 & 90 & 26 & 122 & 43 & 0.35 \\
\hline $\mathrm{tt} 5$ & $12-16$ Oct. 2000 & 212 & 12 & 244 & 127 & 0.52 \\
\hline \multicolumn{7}{|c|}{ Ammer at Fischen $\left(709 \mathrm{~km}^{2}\right)$} \\
\hline $\mathrm{am} 1$ & 16-20 Jul. 1993 & 272 & 39 & 94 & 44 & 0.47 \\
\hline am2 & 27-30 Aug. 1995 & 164 & 39 & 105 & 44 & 0.42 \\
\hline am3 & 17-20 Jul. 1997 & 247 & 28 & 74 & 28 & 0.38 \\
\hline $\mathrm{am} 4$ & 20-24 May 1999 & 184 & 9 & 188 & 108 & 0.57 \\
\hline
\end{tabular}

Acknowledgement: The EU grant ENV 4-CT97-0552 "RAPHAEL" contributed to this work. The Italian Ministry of University and Research grant COFIN 2003 is also acknowledged. Ralf Ludwig and Stefan Taschner kindly contributed by processing the data about the Ammer watershed. 


\section{REFERENCES}

Bacchi, B., G. Grossi, R. Ranzi and A. Buzzi, 2002: On the use of coupled mesoscale meteorological and hydrological models for flood forecasting in midsize mountain catchments: operational experience and verification, Proc. of the $2^{\text {nd }}$ International Symposium on Flood Defence, Beijing, China, 10-13 September 2002, ed. by Wu et al., Science Press, New York Ltd., ISBN 1-880732-54-0, 2, 965-972.

Bacchi B. and R. Ranzi, 2003: Hydrological and meteorological aspects of floods in the Alps: an overview, Hydrol. Earth System Sci., 7(6), 784-798.

Benoit R., Kouwen N., Yu W., Chamberland S. and P. Pellerin, 2003: Hydrometeorological aspects of the realtime ultrafine forecast support during the Special Observing Period of the MAP, Hydrol. Earth System Sci. 7(6), 877-889.

Bougeault P. , P. Binder, A. Buzzi, R. Dirks, R. Houze, J. Kuettner, R. B. Smith, R. Steinacker, and H. Volkert, 2001: The MAP Special Observing Period. Bulletin of the American Meteorological Society, 82 , 433-462 .

Grossi G. and N. Kouwen, Intercomparison among hydrologic simulations coupled to meteorological predictions provided by different mesoscale meteorological models, Proc. $29^{\text {th }}$ Convegno di Idraulica e Costruzioni Idrauliche, 7-10 September 2004, Trento, 2, 265-271, 2004.

Jasper K., J. Gurtz and H. Lang, 2002, Advanced flood forecasting in Alpine watersheds by coupling meteorological observations and forecasts with adistributed hydrologial model, J. Hydrol., 267, 40-52.

Jasper K. and P. Kaufmann, 2003: Coupled runoff simulations as validation tools for atmospheric models at the regional scale, Quart. Journal Royal Meteorol. Soc., Vol. 129 Part B, n. 588, 673-692.

Ludwig, R., S. Taschner and W. Mauser, 2003: Modeling floods in the Ammer watershed - Experiences, limitations and challenges from coupled meteo-hydrological model approach, Hydrol. Earth System Sci. 7(6), 833-847.

Macelloni, G., S. Paloscia, P. Pampaloni, E. Santi and M. Tedesco, 2003: Microwave radiometric measurements of soil moisture in Italy, Hydrol. Earth System Sci. 7(6), 937-948.

Menziani, M., Pugnaghi, S., Vincenzi, S., and Santangelo, R., 2003: Soil moisture monitoring in the Toce Valley (Italy), Hydrol. Earth System Sci. 7(6), 890-902.

Montaldo N., Toninelli V.,Mancini M., and R. Rosso, 2002: Coupling Limited Area Models with Distributed Hydrologic Models for Flood Forecasting: the Toce Basin Case Study, IAHS publ. no. 274.

Ranzi R., 2005: Predictability of floods in the Alps: hydrological aspects., Proc. of the Workshop on "Early Warning of Intense Precipitation and Flash Floods", Ljubljana, 21-22 October 2004 (in press).

Ranzi R., Bacchi B. and G. Grossi, Runoff measurements and hydrological modelling for the estimation of rainfall volumes in an alpine basin, Quart. Journal Royal Meteorol. Soc., Vol. 129 Part B, n. 588, 653-672, 2003.

Zappa, M. and J. Gurtz, 2003: Simulation of soil moisture and evapotranspiration in a soil profile during the 1999 MAP-Riviera Campaign, Hydrol. Earth System Sci. 7(6), 903-919.

Websites of interest:

http://civserv.ing.unibs.it/raphael/

http://www.copernicus.org/EGU/hess/hs7/contents7-6.htm)

http://bsing.ing.unibs.it/ dic-segr/maphyd.htm 